Original article

\title{
Study of tin corrosion: the influence of alloying elements
}

\author{
Ivan De Ryck ${ }^{\text {a }}$, Evelien Van Biezen ${ }^{\mathrm{b}}$, Karen Leyssens ${ }^{\mathrm{c}}$, Annemie Adriaens ${ }^{\mathrm{c}, *}$, \\ Patrick Storme ${ }^{\mathrm{b}}$, Freddy Adams ${ }^{\mathrm{a}}$ \\ ${ }^{a}$ Department of Chemistry, University of Antwerp, Universiteitsplein 1, 2610 Antwerp, Belgium \\ ${ }^{b}$ Department of Conservation/Restoration of Metals, Hogeschool Antwerpen, Royal Academy for Fine Arts, Blindestraat 9-11, 2000 Antwerp, Belgium \\ ${ }^{c}$ Department of Analytical Chemistry, Ghent University, Krijgslaan 281-S12, 9000 Ghent, Belgium
}

Received 8 July 2003; accepted 27 October 2003

\begin{abstract}
This paper focuses on the corrosion behaviour of tin objects stored in museums. A set of authentic objects was investigated using optical microscopy $(\mathrm{OM})$ and scanning electron microscopy with energy dispersive X-ray detection (SEM-EDX). The goal existed in acquiring information on the appearance of the corroded surfaces and the chemical composition of the alloys. The analyses made it possible to obtain an overview of typical corrosion forms seen on ancient tin objects. In order to study the influence of the alloying elements and corrosive agents on the corrosion behaviour, a simulation study was set up in which five ancient alike tin alloys were produced and artificially corroded by using different corrosive agents. The corroded surfaces were analysed using OM, SEM-EDX and Fourier transform infrared spectroscopy (FTIR) and the results were compared with those obtained from the authentic samples.
\end{abstract}

(c) 2004 Elsevier SAS. All rights reserved.

Keywords: Ancient tin alloys; Corrosion; OM; SEM-EDX; FTIR

\section{Research aims}

The objective of this paper is to contribute to a better understanding of the degradation of tin objects present in museum collections. Specific emphasis has been laid on the study of factors which may influence the corrosion, such as the alloying elements and the corrosive agents.

\section{Introduction}

Several publications mention tin to be corrosion resistant. Results have indeed shown that under natural conditions water and atmospheric oxygen have no harmful effects on metallic tin, although tarnishing of tin is sometimes observed in indoor atmospheric conditions [1-3]. Nevertheless, tin may also suffer from corrosion by mineral acids and organic acids in the presence of air [2]. This general idea has in the past led to believe that tin objects stored under normal museum conditions are little affected by atmospheric corrosion. As a result tin pest was often considered as the major dete-

\footnotetext{
* Corresponding author.

E-mail address: Annemie.Adriaens@UGent.be (A. Adriaens).
}

rioration cause of tin objects stored in museums. Tin pest is a physical phenomenon, i.e. an allotropic transformation of metallic white tin $(\beta$-tin) to grey $(\alpha$-tin) which occurs at low temperatures, namely below $13.2{ }^{\circ} \mathrm{C}$. Metallic white tin is very ductile, while grey tin is brittle. Both have different crystallinity and density-white tin $\left(7.29 \mathrm{~g} \mathrm{~cm}^{-3}\right)$ and grey tin $\left(5.77 \mathrm{~g} \mathrm{~cm}^{-3}\right)$ - which result in the transformation of the objects into powder when tin pest occurs [4]. Once an object is harmed by tin pest it will be completely destroyed after a period of time. No treatment is possible in this case. The corrosion of tin on the other hand is (electro)chemical by nature and can be treated in many cases. The most typical and most stable corrosion product of tin is tin(IV)oxide, $\mathrm{SnO}_{2}$ [4].

The general belief that tin is not affected by corrosion, and on the other hand the general assumption that tin pest is the main degradation form of tin objects, has led to the fact that today many of the tin objects which are present in museums are in a certain state of decay. Detailed examination of several museum objects has, however, shown that they were not affected by tin pest but by a certain form of tin corrosion [5-7].

Research on the corrosion of tin objects stored in museums has up to now been relatively limited. A thorough under- 
standing of the mechanisms, however, can contribute to the improvement of conservation strategies. In this work a relevant set of ancient alike tin alloys were produced, artificially corroded and studied with surface analysis methods. The emphasis of this work existed in studying the influence of the alloying elements and the corrosive agents on the obtained corrosion.

\section{Experimental}

\subsection{Analysis of ancient tin objects}

The chemical composition of the ancient alike tin alloys, prepared in this study, was based on a statistical study performed on literature data including results of more than 200 analyses of tin objects with a maximum lead content of $5 \%[6,8,9]$. In addition 16 tin objects were analysed in this work using scanning electron microscopy with energy dispersive X-ray detection (SEM-EDX). The quantification was done with a standard ZAF method using PGT quantification software with user supplied standards. For the analysis we were allowed to sample a small piece of every object using a jeweller's piercing saw. Fourteen of the sampled objects (eight spoons and six lids of jugs) are kept at the museum Sterckshof in Antwerp (Belgium). The tin beaker originates from the city of Zoutleeuw (Belgium) and the water urn is kept at the museum Smidt-van Gelder in Antwerp. The compositional results of the examined ancient objects are shown in Table 1, the uncertainty is below $5 \%$ of the value.

\subsection{Production of ancient alike alloys}

Based on the above-mentioned results and the literature search, a total of five alloys were produced with the following composition: (1) pure tin, (2) tin including $2.5 \%$ lead, (3) tin with $0.035 \%$ antimony, (4) and (5) tin with copper $(0.5 \%$ and $2 \%)$. The alloys were prepared by weighting the appropriate amount of pure metals (see Table 2) in powder form or

Table 1

Composition of the analysed tin alloys. (nd: not detected)

\begin{tabular}{lllll}
\hline & $\mathrm{Sn}(\mathrm{wt} . \%)$ & $\mathrm{Cu}(\mathrm{wt} . \%)$ & $\mathrm{Pb}(\mathrm{wt} . \%)$ & $\mathrm{Fe}(\mathrm{wt} . \%)$ \\
\hline Lid 1 & 94.9 & 0.7 & 4.4 & $\mathrm{nd}$ \\
Lid 2 & 78.9 & 0.5 & 20.5 & 0.1 \\
Lid 3 & 56.5 & 0.3 & 43.1 & 0.1 \\
Lid 4 & 90.6 & 0.8 & 8.6 & 0.1 \\
Lid 5 & 61.9 & 0.4 & 37.7 & 0.1 \\
Lid 6 & 96.3 & 0.8 & 2.8 & 0.1 \\
Spoon 1 & 98.9 & 1.1 & nd & nd \\
Spoon 2 & 98.1 & 1.8 & nd & nd \\
Spoon 3 & 94.5 & 0.8 & 4.4 & nd \\
Spoon 4 & 98.4 & 1.3 & nd & nd \\
Spoon 5 & 98.5 & 1.4 & nd & nd \\
Spoon 6 & 97.5 & 0.8 & 1.7 & 0.1 \\
Spoon 7 & 97.3 & 1.9 & 0.8 & 0.1 \\
Spoon 8 & 86.7 & 3.8 & 9.4 & 0.2 \\
Beaker & 98.5 & 1.2 & nd & nd \\
Water urn & 97.6 & 2.4 & nd & nd \\
\hline
\end{tabular}

Table 2

Weighted amount of metal and AAS results of the prepared tin alloys

\begin{tabular}{llccl}
\hline Alloy & $\begin{array}{l}\text { Amount } \\
\text { Sn }(\mathrm{g})\end{array}$ & $\begin{array}{l}\text { Amount } \\
\text { alloy }(\mathrm{g})\end{array}$ & $\begin{array}{l}\text { Tin content } \\
(\text { wt.\%) }\end{array}$ & $\begin{array}{l}\text { Content of } \\
\text { alloying element } \\
\text { (wt.\%) }\end{array}$ \\
\hline $\mathrm{Sn}$ & 57.24 & 0 & 100 & - \\
$\mathrm{Sn}-\mathrm{Pb}$ & 54.37 & 1.43 & 97.44 & 2.56 \\
$\mathrm{Sn}-\mathrm{Sb}$ & 57.29 & 0.28 & 99.965 & 0.035 \\
$\mathrm{Sn}-0.5 \% \mathrm{Cu}$ & 57.29 & 0.28 & 99.54 & 0.46 \\
$\mathrm{Sn}-2 \% \mathrm{Cu}$ & 56.08 & 1.14 & 98.01 & 1.99
\end{tabular}

granules (Merck) and mixing them together. The following products were used: tin granules pro analysi (particle size $4 \mathrm{~mm}$ ); lead coarse powder pro analysi; antimony powder pro analysi (particle size $<150 \mu \mathrm{m}$ ); copper fine powder (particle size $<62 \mu \mathrm{m})$ pro analysi. The tin granules were melted in a ceramic crucible using an electric furnace which was heated to approximately $400{ }^{\circ} \mathrm{C}$. After the tin granules were melted completely, the alloying element was added to the melt in solid condition, which was stirred with a quartz stirring rod. In case of the copper containing alloys a small amount of ammonium chloride was added to prevent the oxidation of the copper particles. After thorough stirring, the liquid alloy was poured into a preheated $\left(100-150{ }^{\circ} \mathrm{C}\right)$ cast iron mould. After 5 min of cooling time into the mould, the metal was removed and allowed to cool further in the air. Metal plates of $7 \mathrm{~cm} \times 4 \mathrm{~cm} \times 0.28 \mathrm{~cm}$ were obtained (small pieces of $1.5 \mathrm{~cm}$ $\times 2 \mathrm{~cm}$ were cut for the artificial corrosion). The samples show a typical as cast structure with columnar crystals at the outer edges and equiaxial grains in the centre of the metal plate. SEM-EDX results show no segregation of the alloying elements at the outer surface occurs. However, metallic inclusions occur for the tin alloys containing $\mathrm{Cu}$ and $\mathrm{Pb}$, as expected from the phase diagrams.

The composition of the alloys was determined by atomic absorption spectrometry (AAS). The sample preparation for these analyses included the dissolution of $0.5 \mathrm{~g}$ alloy into $5 \mathrm{ml}$ hydrochloric acid ( $\mathrm{HCl}$ ) (pro analysi, 50\%) with the addition of $5 \mathrm{ml}$ nitric acid $\left(\mathrm{HNO}_{3}\right.$ ) (pro analysi, $50 \%$ ) under slight heating. In a second step the solution was diluted down to $100 \mathrm{ml}$ using Milli-Q water. These samples were analysed in triplicate using a Perking Elmer 3030 AAS. The results are shown in Table 2 . The uncertainty is below $2 \%$ of the value.

\subsection{Corrosion simulation}

Artificial corrosion was generated by chemical treatment under highly acidic conditions using sulphuric acid $\left(\mathrm{H}_{2} \mathrm{SO}_{4}\right)$, $\mathrm{HNO}_{3}, \mathrm{HCl}$, all three in a $1 \mathrm{M}$ aqueous solution and a combination of these three acids each at $0.33 \mathrm{M}$. These reagents were chosen since it is known that in normal atmospheric conditions particles containing $\mathrm{SO}_{4}{ }^{2-}, \mathrm{NO}_{3}{ }^{-}$and $\mathrm{Cl}^{-}$ are present. The salts containing these can affect tin; however, to come to a more rapid development of corrosion we chose to use the acids associated with these ions. In a previous study three different methods were examined for the reaction of the acids with the alloys: (1) the acids as gaseous 
environment, (2) immersion of the alloys into the acid solution and (3) by dropping small amounts of acid onto the alloy [4]. Based on these results, the drop method was chosen as the most rapid and most successful method to create a corrosion layer with a similar appearance to the corrosion one finds on ancient objects. The various samples were corroded by forming small drops of the solutions twice a day during 3 weeks on the surface of the samples. To speed up the corrosive action, the samples were kept at a temperature of $40{ }^{\circ} \mathrm{C}$.

\subsection{Sample preparation for surface analysis}

The characterisation of the corrosion products was performed using optical microscopy (OM), Fourier transform infrared spectroscopy (FTIR) and SEM-EDX.
The first step involved the visual characterisation at different magnifications using OM and SEM, after which the non-adhered corrosion products of the artificially corroded samples were brushed off the sample. These loose corrosion products were investigated using FTIR to obtain molecular information. The sample preparation for these measurements included the mixture of $0.008 \mathrm{~g}$ sample with $0.392 \mathrm{~g}$ of $\mathrm{KBr}$ in a mortar. As a blanc measurement $0.4 \mathrm{~g} \mathrm{KBr}$ was used. Reference samples included $\mathrm{SnO}, \mathrm{SnO}_{2}, \mathrm{CuO}, \mathrm{CuSO}_{4}$ and hydrated $\mathrm{CuNO}_{3}$ were recorded in the same way as the samples. Other reference spectra were obtained from the literature [10-13].

The samples were embedded in a resin, grinded using silicon carbide paper and polished with diamond sprays of decreasing grain sizes to $0.25 \mu \mathrm{m}$. Cross sections of samples were made and were investigated with SEM-EDX after car-


Fig. 1. Typical examples of surface corrosion features on authentic tin artefacts: optical images a-e show different types of corrosion holes apparent at the surface. Images a-b, holes that are punctured through the surface; images d-e, shallow holes with some residual corrosion products left in; image 1c, an example of a corrosion crack; images $\mathrm{f}$ and $\mathrm{h}$, spots consisting of dark grey to black corrosion products; image i shows examples of white loose corrosion products. Noteworthy is the fact that for most of the examined objects more than one feature at the same time could be observed. 
bon coating. Artificial samples as well as the ancient samples were prepared in this manner. The cross sections allowed us to study the structure of the corrosion layers using secondary electron imaging (SEI) and backscattered electron imaging (BSEI). The elemental distribution in the corrosion layer was studied using X-ray mappings.

\section{Results and discussion}

\subsection{Ancient alloys}

Optical micrographs of the ancient objects showed a dull grey to black surface. In some cases, the original lustrous metallic looking surface could still be distinguished inbetween the tarnished isles. Different corrosion features could be observed such as cracks, holes and pits with residual loose sitting dark grey corrosion. The images shown in Fig. 1 represent typical examples.

SEM results of the cross sections show the presence of a corrosion layer with a typical thickness between 10 and $100 \mu \mathrm{m}$. In most of the cases the corrosion consists of a well adhering single layer, of which the appearance is variable depending on the sample and the location on the sample. However, evidence of a second loosely adherent layer was recovered from some of the samples. The BSE images shown in Fig. 2 give an overview of some of the typical corrosion shapes, including an example of pitting and intergranular corrosion. An example of intergranular like corrosion is shown in Fig. 2d.

From Table 1, it appears that the samples can be divided into two main groups of tin artefacts: $\mathrm{Sn}-\mathrm{Cu}$ alloys $(\mathrm{Cu}>1$ wt.\%, with most often Fe "traces") and $\mathrm{Sn}-\mathrm{Pb}$ alloys (with two sub-groups: high and low $\mathrm{Pb}$ content). At first sight there is no obvious relation between the composition and the appearance of the surface of the alloy. However, examining the cross sections with SEM it appears that the corrosion of the $\mathrm{Cu}$ containing alloys mainly consist of a single well adhering corrosion layer, with for some samples evidence of a second loosely adherent layer (Fig. 2a). For the samples containing $\mathrm{Pb}$ on the other hand the corrosion becomes more intergrannular of nature (Fig. 2d). In many cases corrosion cracks are observed which shows that the corrosion seems less adherent to the surface.

According to the SEM-EDX analyses the corrosion layer consists primarily of tin and oxygen, which indicates that the layer is composed of tin oxides and tin hydroxides as mentioned in the literature [1]. For a few samples containing $\mathrm{Cu}$ but no $\mathrm{Pb}$, a second thin layer containing chlorine in between the corrosion and the metal could be observed. This $\mathrm{Cl}^{-}$ containing layer is only a few micrometres thick. Further-
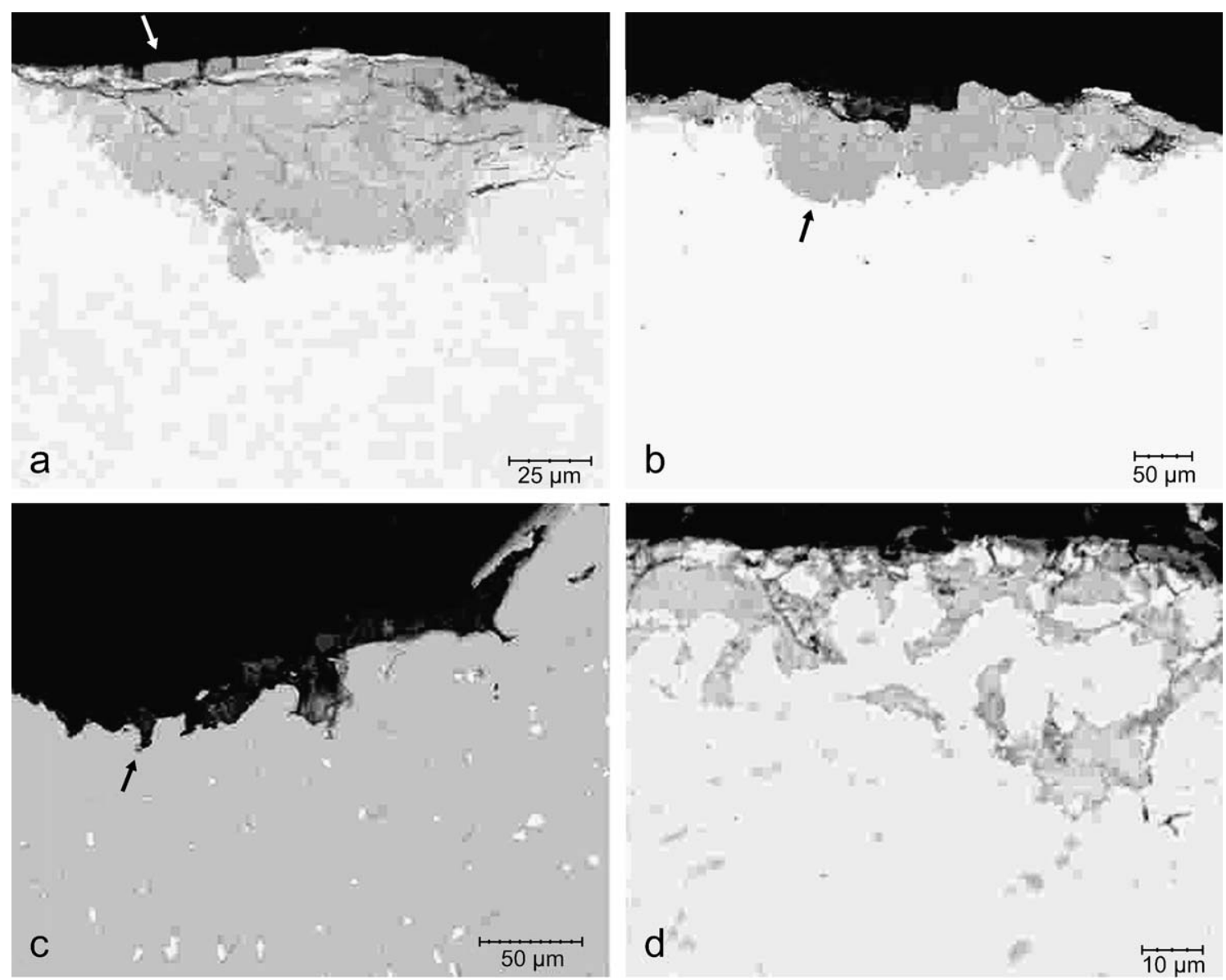

Fig. 2. BSE images obtained from the cross sectioned samples of the ancient tin objects. The images give an overview of some typical encountered corrosion forms on these objects. 
Table 3

Visual appearance of the artificially corroded surfaces examined by OM and SEM

\begin{tabular}{lll}
\hline $\begin{array}{l}\text { Reactive } \\
\text { agent }\end{array}$ & Appearance of the as-produced corroded surface examined by OM & Structure and appearance of the corrosion layers examined by SEM \\
\hline $\mathrm{H}_{2} \mathrm{SO}_{4}$ & $\begin{array}{l}\text { Crystalline-looking adhered layer with additional loose amorphous } \\
\text { material, colour: grey }\end{array}$ & Loose upper layer and adhered inner layer, fibre like features \\
$\mathrm{HNO}_{3}$ & $\begin{array}{l}\text { Amorphous-looking loose layer on top of adhered layer, colour: white- } \\
\text { yellow }\end{array}$ & Loose upper layer and adhered inner layer, hemispherical pit corrosion \\
$\mathrm{HCl}$ & Amorphous-looking adhered layer, colour: grey & Loose upper layer and adhered inner layer, sharp triangular pit corrosion \\
$\mathrm{Combina}-$ & $\begin{array}{l}\text { Amorphous-looking adhered layer except for the alloy containing } 2 \% \\
\text { Cu (appearance of corrosion is similar as for } \mathrm{H}_{2} \mathrm{SO}_{4} \text { ), colour: white- corrosion features } \\
\text { tion }\end{array}$ & $\begin{array}{l}\text { yellow } \\
\end{array}$
\end{tabular}

more, in a number of cases a loose sitting layer on top of the adhered layer was found containing also oxygen and tin (Fig. 2a). For the $\mathrm{Sn}-\mathrm{Cu}$ alloys it appears that during the corrosion process the $\mathrm{Cu}$ of the $\mathrm{Cu}$ metallic inclusions is not diffused/dissolved into the corrosion layer. This means that distinct copper inclusions remain visible in the corrosion layer. In a number of cases this is different for the $\mathrm{Cu}$ holding $\mathrm{Sn}-\mathrm{Pb}$ alloys, where the $\mathrm{Cu}$ tends to be dissolved into the corrosion layer. In this case no distinct $\mathrm{Cu}$ inclusions are observed in the corrosion layer. In addition the $\mathrm{Pb}$, from $\mathrm{Pb}$ rich phases present in the alloy, is also dissolved homogeneously into the corrosion crust for most of the examined samples.

No specific molecular information on the corrosion compounds of the objects examined was obtained, since FTIR analysis seemed to be impossible. However, in the literature it is mentioned that $\mathrm{Sn}$ and $\mathrm{O}$ containing compounds such as cassiterite $\left(\mathrm{SnO}_{2}\right)$, romarchite $(\mathrm{SnO})$ and hydroromarchite $\left(5 \mathrm{SnO} \cdot 2 \mathrm{H}_{2} \mathrm{O}\right)$ are observed on corroded tin objects $[14,15]$. Furthermore the presence of tin(II)chloride $\left(\mathrm{SnCl}_{2}\right)$, basic tin(II)chloride $\left(\mathrm{Sn}_{2} \mathrm{OCl}_{2}\right)$, basic tin(II)sulphate $\left(\mathrm{Sn}_{3} \mathrm{O}_{2} \mathrm{SO}_{4}\right)$ on archaeological objects is also reported in the literature [14-16]. Apart from these elements $\mathrm{Si}, \mathrm{Fe}$ and $\mathrm{Ca}$ were observed on some of the investigated ancient alloys. These elements are typically associated with dust/soil particles captured in the corrosion layer.

\subsection{Ancient alike alloys, artificially corroded}

The as-produced surfaces were in first instance examined using OM and SEM-EDX and showed for all samples a profound similarity in the appearance of the corrosion in case the same corrosive agent was used. The use of different reagents, however, resulted in corroded surfaces with a different appearance. A summary of these results is given in Table 3.

FTIR analyses of the brushed-off material show mainly the presence of tin oxides. $\mathrm{H}_{2} \mathrm{SO}_{4}$ corroded samples showed in addition the presence of tin sulphate $\left(\mathrm{SnSO}_{4}\right)$ and nitrates were observed when $\mathrm{HNO}_{3}$ was the corrosive agent. In the latter case the overlap of IR absorption bands generated by nitrates, oxides and hydroxides made it impossible to make a differentiation between oxides and hydroxides of tin. Finally the FTIR data obtained for the corrosion generated with the acid combination shows the presence of $\mathrm{SnO}_{2}$ as well as sulphates and nitrates. Again in this case it is impossible to differentiate between tin(II)oxide and of tin hydroxides due to peak overlap. Fig. 3 shows a detail of the FTIR spectrum obtained from the $\mathrm{Sn}-\mathrm{Cu} 1.5 \mathrm{wt} . \%$ alloy. The bands at 1184 , $1072,982,654,592$ and $472 \mathrm{~cm}^{-1}$ correspond to vibrations of $\mathrm{SnSO}_{4}$ [10]. The bands at $669,654,615$ and $411 \mathrm{~cm}^{-1}$ correspond to vibrations of $\mathrm{SnO}_{2}$ [13]. It was impossible to allocate the vibration bands around 900 and $840 \mathrm{~cm}^{-1}$ to a specific compound. Additionally broad absorption bands, originating from $\mathrm{OH}$ vibrations, in the $2200-3500 \mathrm{~cm}^{-1}$ region are observed.

SEM images of the cross sections show that in general the corrosion layer is composed of a loose upper layer and an adhered inner layer. Also the effect of the reagents is clearly visible. The results are summarised in Table 3. A few typical examples are shown in Fig. 4.

When the thickness of the corrosion layer is considered (Table 4), it is clear that all of the alloys are strongly affected by $\mathrm{HNO}_{3}$ and also by $\mathrm{HCl}$, except for the $\mathrm{Pb}$ containing alloy which is less affected by $\mathrm{HNO}_{3}$ compared to the other alloys. $\mathrm{H}_{2} \mathrm{SO}_{4}$ produces the thinnest layers without exception. As could be expected, the combination of acids shows an intermediate corrosion thickness. Apart from the influence of the reagents, the corrosion thickness is also influenced by the alloying element. The sensitivity of the tin alloys to the corrosive action of $\mathrm{H}_{2} \mathrm{SO}_{4}$ and $\mathrm{HCl}$, compared to pure tin, increases when $\mathrm{Sb}$ and $\mathrm{Cu}$ are added. Compared to pure $\mathrm{Sn}$, the $\mathrm{Cu}$ alloy is more affected and the $\mathrm{Sb}$ containing alloy is

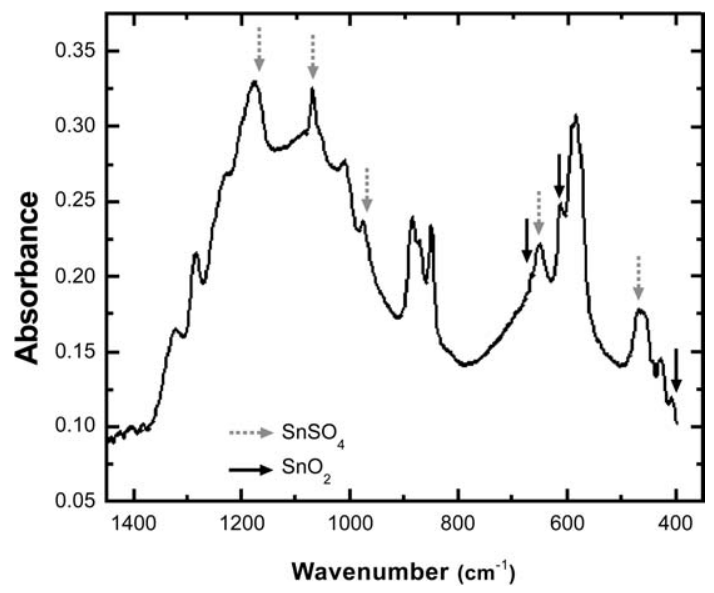

Fig. 3. FTIR-spectrum obtained from an artificially corroded $\mathrm{Sn}-\mathrm{Cu}$ 1.5 wt. \% alloy using a $1 \mathrm{M}$ solution of $\mathrm{H}_{2} \mathrm{SO}_{4}$. 

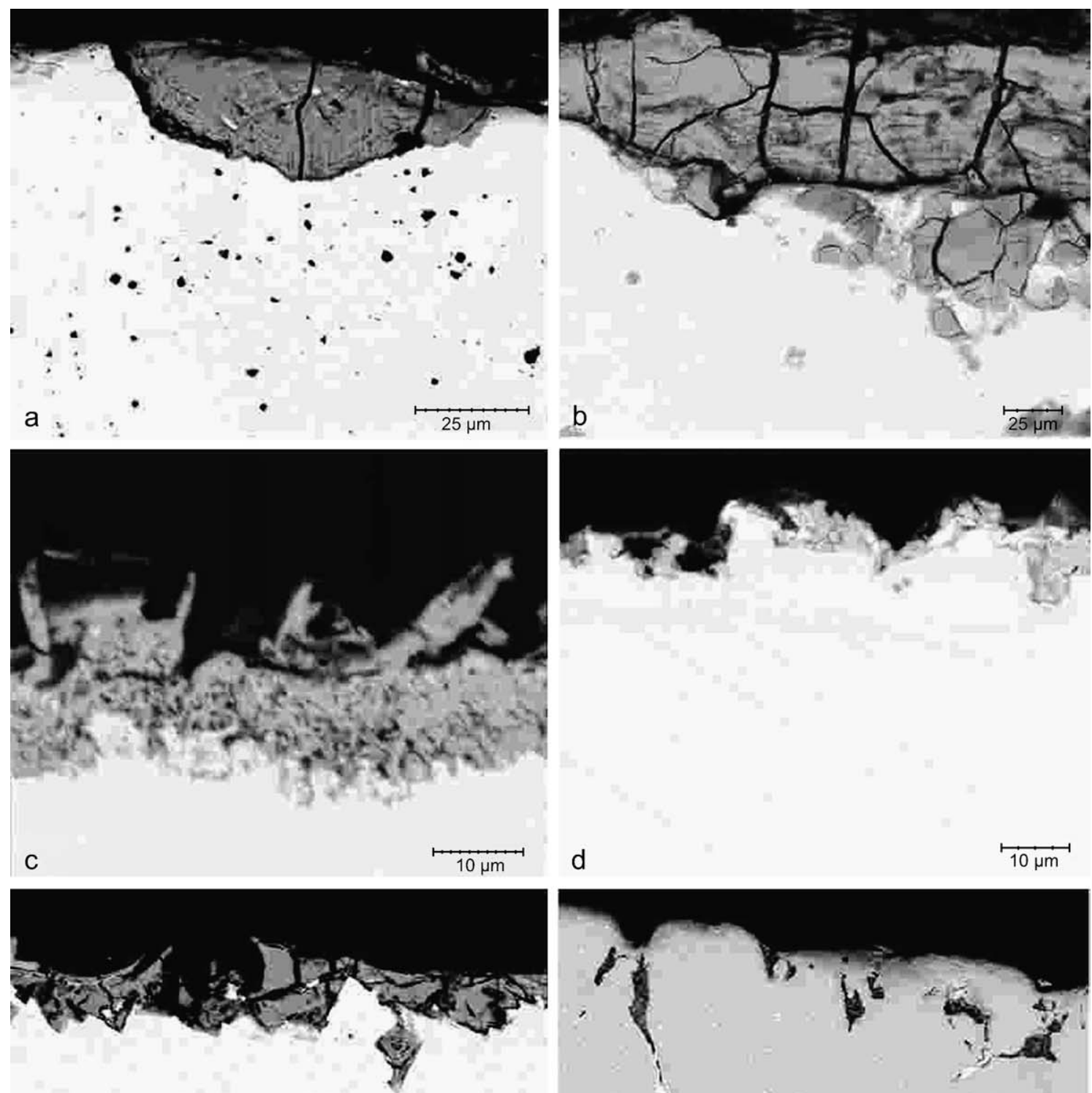

d

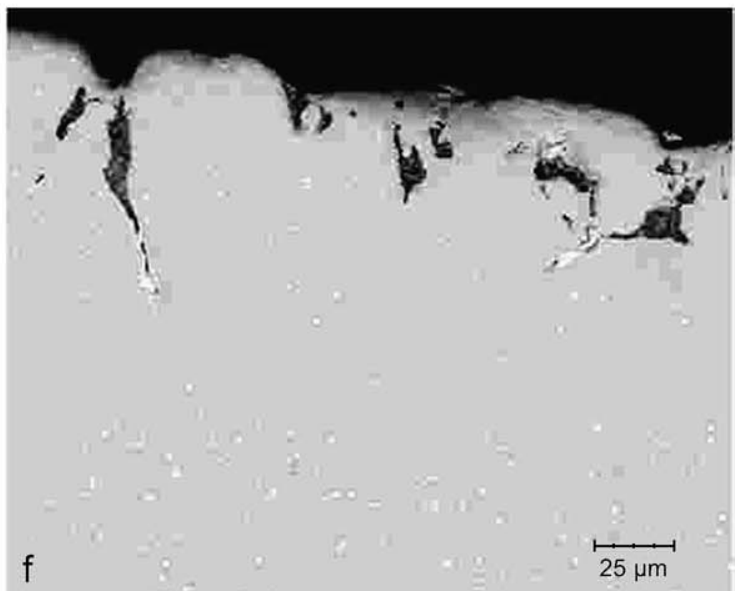

Fig. 4. BSE images obtained from the cross section of artificially corroded tin alloys. Images a-b show hemispherical pitting corrosion generated by $\mathrm{HNO}_{3}$. Images $\mathrm{c}-\mathrm{d}$ show irregular shaped corrosion generated by $\mathrm{HNO}_{3}$ and images $\mathrm{e}-\mathrm{f}$ show corrosion generated by $\mathrm{HCl}$.

Table 4

Thickness of corrosion layer $(\mu \mathrm{m})$ for different alloys and different treatments measured using SEM images

\begin{tabular}{lllll}
\hline & $\mathrm{H}_{2} \mathrm{SO}_{4}$ & $\mathrm{HNO}_{3}$ & $\mathrm{HCl}$ & Combination \\
\hline Pure tin & 7.5 & 50 & 14 & $35-50$ \\
Lead alloy & 5 & 15 & 60 & 10 \\
Antimony alloy & $15-50$ & 25 & 25 & 25 \\
0.5\% Copper alloy & 15 & 70 & 41 & 20 \\
$2 \%$ Copper alloy & 8 & 70 & 80 & 30 \\
\hline
\end{tabular}

less affected when $\mathrm{HNO}_{3}$ is the corrosive agent. The combination of acids shows decreased corrosion sensitivity for all of the alloys studied. The addition of $\mathrm{Pb}$ reduces the corrosion sensitivity, except when $\mathrm{HCl}$ is the aggressor. In the latter case the corrosion sensitivity is increased compared to pure tin.

\subsection{Comparison of ancient and ancient alike corrosion}

Similarities on a visual basis between the authentic corrosion on the museum objects and the simulated corrosion 
could be seen. For example, the white yellow corrosion seen on the surface of the ancient tin objects could also be observed on the tin alloys corroded with $\mathrm{HNO}_{3}$. The surface of the tin alloys corroded using $\mathrm{HCl}, \mathrm{H}_{2} \mathrm{SO}_{4}$ and the combination of acids was grey-black of colour, as were the corrosion products found on ancient tin alloys. The difference between the ancient and the modern tin alloys, however, is that the corrosion on the ancient alloys does not have a uniform appearance across the entire object. Furthermore a loose corrosion layer was present for all the artificially corroded alloys. The absence of this loose corrosion layer on the ancient objects does not necessarily mean that these products are not formed. Since the corrosion is not adhered to the surface it can be easily rubbed off. However, for some objects parts of a residual loose corrosion layer were observed (Fig. 2a: the arrow indicates the loose corrosion product).

The resemblance between the cross sections for both the ancient and the modern alloys is great, especially if the interface between the corrosion and the metal is considered. For example $\mathrm{Sn}$ and $\mathrm{O}$ are dominantly present in the corrosion layer for both the ancient and ancient alike sample. Moreover IR-spectra of the compounds on the ancient alike alloys $\mathrm{SnO}_{2}$ and the possible presence of $\mathrm{SnO}$ and tin oxide hydrates are attesting the similarities with the ancient alloys. Also the presence of $\mathrm{Cl}$ and $\mathrm{S}$, where $\mathrm{S}$ was observed under the form of $\mathrm{SnSO}_{4}$, in the ancient alike corrosion layer is an evidence for the similarity between both samples. Besides these similarities some differences were also encountered. For example for the ancient alike alloys nitrates were observed when the aggressor contained $\mathrm{HNO}_{3}$, while for the ancient alloys no nitrates were attested until now. Furthermore the presence of elements typically associated with dust/soil particles such as $\mathrm{Fe}, \mathrm{Ca}$ and $\mathrm{Si}$ were found to be absent in case of the ancient alike alloys. This is not surprising since the corrosion was generated in well controlled laboratorial environment.

Different corrosion behaviour between the ancient $\mathrm{Sn}-\mathrm{Pb}$ and $\mathrm{Sn}-\mathrm{Cu}$ alloys appears. The observations on the artificially corroded tin alloys confirm the different corrosion behaviour of $\mathrm{Sn}-\mathrm{Pb}$ alloys compared to $\mathrm{Sn}-\mathrm{Cu}$ alloys. In general for the artificially corroded $\mathrm{Sn}-\mathrm{Cu}$ alloys, the $\mathrm{Cu}$ corrosion compounds remain as inclusions in the corrosion layer. In contrast for the $\mathrm{Pb}-\mathrm{Sn}$ alloys, the $\mathrm{Pb}$ compounds present in the artificial layer tend to be distributed into the corrosion layer. This is similar to the observations made for the authentic objects. Also the structure of the corrosion was different for the authentic $\mathrm{Sn}-\mathrm{Pb}$ and $\mathrm{Sn}-\mathrm{Cu}$ alloys where an adherent layer was observed for the $\mathrm{Cu}$ containing alloy, an intergranular cracked structure was observed for some of the $\mathrm{Pb}$ alloys. Similar differences were observed for the synthetic corrosion. However, for the corrosion generated by $\mathrm{HNO}_{3}$, the $\mathrm{Cu}-\mathrm{Sn}$ alloy showed also corrosion cracks, resulting in a less adhering corrosion layer. In comparing the results ob- tained on ancient tin objects, where natural aggressive conditions are prevalent, with those obtained artificially under high acidic conditions one must be careful. Nevertheless, it is clear that the besides the corrosive environment, alloying elements influence the corrosion behaviour of Sn alloys.

\section{Conclusion}

The results have shown that it is possible to generate ancient alike corrosion structures on recently created tin alloys by using the drop method. This method in particular has shown to be useful for studying the influence of alloying elements on the corrosion behaviour of tin alloys.

The results have further demonstrated the influence of the corrosive agent and the alloying elements on the corrosion behaviour of tin alloys. In general the addition of $\mathrm{Sb}$ and $\mathrm{Cu}$ increases the corrosion sensitivity of the alloy, while the addition of $\mathrm{Pb}$ (except in $\mathrm{HCl}$ ) reduces the sensitivity in highly acidic solutions. It was also seen that the alloys were more affected by $\mathrm{HNO}_{3}$ and $\mathrm{HCl}$ then by $\mathrm{H}_{2} \mathrm{SO}_{4}$.

\section{References}

[1] T. Stambolov, The Corrosion and Conservation of Metallic Antiquities and Works of Art, Central Research Laboratory for Objects of Art and Science, Amsterdam, 1985.

[2] S.C. Britton, The Corrosion Resistance of Tin and Tin alloys, Tin Research Institute, 1952.

[3] H. Leidheiser, The Corrosion of Copper, Tin and their Alloys, Wiley, New York, 1971.

[4] E. Van Biezen, E.O. Stannum, naar Structuur en Corrosie van Tin, Royal Academy for Fine Arts, Antwerp, Belgium, 2001 Master thesis.

[5] F. Lihl, On the cause of tin decay in the Sarcophagi of the "Kapuzinergruft", Studies in Conservation 7 (1962) 95-105.

[6] H.J. Plenderleith, R.M. Organ, The decay and conservation of museum objects of tin, Studies in Conservation 2 (1953) 63-72.

[7] C. Worth, D.H. Keith, On the treatment of Pewter plates from the Wreck of La Belle, 1686, The International Journal of Nautical Archaeology 26 (1) (1997) 65-74.

[8] J.H. Carlson, Analysis of British and American Pewter by X-ray fluorescence spectroscopy, Winterthur Portofolio 12 (1977) 66-85.

[9] J.H. Carlson, X-ray fluorescence analysis of Pewter: English and Scottish measures, Archaeometry 19 (2) (1977) 147-155.

[10] V.C. Farmer, The Infrared Spectra of Minerals, Mineralogical Society, London, 1974.

[11] J.R. Ferroro, The Sadtler Inrared Spectra Handbook of Minerals and Clays, Sadtler Research Laboratories, Philadelphia, 1982.

[12] C.J. Pouchert, The Aldrich Library of FT-IR Spectra, first ed, Aldrich Chemical Company, Milwaukee, 1985.

[13] B.X. Huang, P. Tornatore, Y. Li, IR and Raman spectroelectrochemical studies of corrosion films on tin, Electrochimica Acta 46 (2000) 671-679.

[14] I.D. McLeod, Formation of marine concretions on copper and its alloys, International Journal of Nautical Archaeology 11 (1975) 267275.

[15] C.O. Bannister, Note on the corrosion of an ancient tin specimen, Journal of the Institute of Metals 35 (1926) 71-74.

[16] P. Paulitsch, S. Wittmer, Zur Zinnkorrosion an Kunstwerken, Materialwissenschaften und Werkstofftechnieken 20 (1989) 165. 